\title{
Entrepreneurship Determinants of Artisans/Craftsmen in Kumasi Metropolis, Ghana
}

\author{
Isaac Tweneboah-Koduah1, Charles Adusei ${ }^{2 *}$ \\ ${ }^{1}$ Department of Managerial Sciences, Faculty of Business Studies, Garden City University College, Kumasi, Ghana \\ ${ }^{2}$ Department of Accounting, Finance and Banking, Faculty of Business Studies, Garden City University College, \\ Kumasi, Ghana \\ Email: "sircharly2002@gmail.com
}

Received 29 December 2015; accepted 23 February 2016; published 26 February 2016

Copyright (C) 2016 by authors and Scientific Research Publishing Inc.

This work is licensed under the Creative Commons Attribution International License (CC BY). http://creativecommons.org/licenses/by/4.0/

(c) (i) Open Access

\begin{abstract}
A review of entrepreneurship literature suggests that entrepreneurial activities are the most important drivers for economic growth. The study sought to determine the predictors that bring about entrepreneurship for artisans and craftsmen in Kumasi Metropolis. Primary data were gathered from artisans and craftsmen in the market and firms through questionnaires in a criteria-based random survey. The findings of the study revealed the determinant factors of individual, firm and the environmental issues as predictors for the sampled respondents. The determinants were also ranked in relative importance and highlighted the challenges faced by the artisans and craftsmen in Kumasi Metropolis. The study recommends that necessary attention should be given to high ranked determinants so as to increase entrepreneurial processes and activities to alleviate poverty from Kumasi Metropolis through stimulation of economic growth, employment generation, and organizations empowerment.
\end{abstract}

\section{Keywords}

Entrepreneurship, Entrepreneurial Processes, Artisans and Craftsmen, Ghana

\section{Introduction}

According to [1] on the Ghana Millennium Development Goals Report, poverty still remains high in Sub-Sahara Africa, but Ghana’s economic growth performance has been acknowledged as one of the best in the region from

\footnotetext{
${ }^{*}$ Corresponding author.
} 
the 1980s. However this impressive growth performance has not been able to generate into decent employment and eradication of income inequality. Employment to population ratio for Ashanti Region dropped from 68.4\% in 2000 to $64.8 \%$ in 2010 population census as reported by [2] for which Kumasi Metropolis is its capital town; the second largest commercial city in Ghana is faced with lots of unemployment and poverty challenges. Several scholars posit that one of the best ways to curb this situation is through entrepreneurial activities [3] [4]. Entrepreneurship has been proven to be one of the major factors that positively affect the economy of a nation and the quality of life of the people [5]. Lots of researches have also established that entrepreneurial activities and processes have a positive relationship with the stimulation of economic growth, employment generation, and empowerment of the disadvantage segment of the population which include women and the poor [6].

The subject of entrepreneurship however suggests that three key factors must exist for entrepreneurial processes and activities such as opportunities identification and subsequent development of opportunities to evolve. These are individual, firm, and environmental capabilities. Available literature maintains that individuals are the main carriers of entrepreneurial activities and processes. Individuals bring together the factors of entrepreneurship and also bear all the risks involved in entrepreneurship. Without the initiation of an individual in entrepreneurship, there will be no entrepreneurial activity [7]. The firm (or organization) capabilities imply that differences in the forms of organizations have an effect on the success of opportunity identification and entrepreneurial activities [3]. Entrepreneurship capabilities assert that entrepreneurship operates in an environment and also nourish by this same environment. Entrepreneurial activity can either grow or die depending upon the nutrients of environment it operates.

Artisans and craftsmen are known as individuals with special skills for manual production of products. They are gifted so much that they can make products from simple materials. This sector provides work to majority of people in the developing country but most of these people live in poverty [8]. Their works include paintings, arts, weaved cloth, carpentry, furniture works, earth work like pottery, cane work like basket, metal works, dress making, hair making, shoe or sandals making, plumbing, goldsmith, brass smith, carving, drum making and more. Most of these artisans and craftsmen go through apprenticeship before setting up their own shop. Few go through training in vocational schools whilst very few attain their skills from higher institutions like the polytechnics and universities. Majority of artisans and craftsmen in Ghana are on a small scale and very few are entrepreneurial in their work. The study therefore seeks to explore the entrepreneurship determinants of Artisans/ craftsmen in the Kumasi Metropolis.

\section{Literature Review}

\subsection{Enterprise, Entrepreneurs and Entrepreneurship}

Enterprise can be explained as business set up which is operated by individuals and often found within the size range of Small and Medium Size Enterprises (SMEs). Entrepreneur represents an individual ability and attitude to spot, create and exploit business opportunities to create wealth through the use of innovation, imagination, and risk-taking. The entrepreneur creates and operates the enterprise, and in doing so displays the characteristic of entrepreneurship [9]. The process of starting a business through its growth and sustaining the business can be termed as entrepreneurship.

Entrepreneurs are frequently thought to be individuals who discover market needs and launch new firms to meet those needs. They are risk takers who provide an impetus for change, innovation, and progress in economic life, [10]. Entrepreneurship is the process of identifying opportunities for which marketable needs exist and assuming the risk of creating an organization to satisfy them. An entrepreneur needs the vision to spot opportunities and the ability to capitalize on them [11]. Entrepreneurship is defined as the process by which individuals pursue opportunities without regard to resources they currently control [12].

[10] defined entrepreneurial opportunity as an economically attractive and timely opportunity that creates value for interested buyers or end users, distinguishes between opportunities and ideas. It is important to note, however, that a given opportunity will not be equally attractive to everyone. Because of differences in experiences and perspectives, one person may see an opportunity where others do not. But, in any case, a true opportunity exists only for the entrepreneur who has the interest, resources, and capabilities required to succeed. Entrepreneurial activities and processes face several challenges from start-up to development. Few of these challenges are associated with the entrepreneur, whilst others will be associated with the organizations' management and its internal environment and the final one will be associated with the environment in which the in- 
dividual and the organization thrive.

The main challenge associated to the individual is his inability to upgrade himself through training. The training that an individual may attain to broaden his horizon include marketing, production, customer care and technical. Little or no knowledge in such areas will greatly affect the entrepreneurial activities. The firm's associated challenges includes; inability to supply the needed resources for entrepreneurial activities, inability to give the enabling environment for entrepreneurial activities and inability to give the needed training to employees. The challenges associated with the environment are numerous. These include unsupportive policies for entrepreneurial activity growth, difficult access to capital, ineffective patent laws, unavailability of patents, unstable consumers' taste and tariffs. Technological forces are also a major challenge to entrepreneurial activities and processes.

\subsection{Determinants of Entrepreneurial Activities}

The individual capacities, the firm variables and the environmental variables that influence new business startup, grow and sustain it are discussed below.

\subsubsection{Individual Capabilities}

Lot of factors cause an individual to start up a new company; introduces a new product, services and a new market. These factors are grouped into psychological factors (personal traits) and non-psychological factors (capability set) as cited by [13]. The psychological factors include need for achievement, risk taking, desire for independence, locus of control, self-efficacy, over confidence, determination or tenacity and intuition. Nonpsychological factors may include but not limited to these: desire for profit, higher level of education, prior experience (for example in career life, general business, functional, industry, start-up), social network, demographics thus gender and age of the individual, and parent's job [14]. Another factor is the individual strong and weak relationships or ties [15]. Independence is one of the reasons entrepreneurs give for starting their own businesses [16]. [11] becoming a boss of one's own company is a drive for an individual to venture into entrepreneurial activities and processes.

\subsubsection{Firm Level Factors}

The following factors were stated by [17] as drivers of entrepreneurial processes and activities in the private sector firm: management support, work discretion, reward/reinforcement, time availability and organization boundaries. This is expressed in various ways like adopting innovative ways of processes, identifying and grooming new entrepreneurial ideas, supporting promising projects, providing expertise and instituting entrepreneurial activity in the system [12].

\subsubsection{Environmental Factors}

The types of environment which entrepreneurial activities and processes take place affect its success [18]. A conducive and enabling socio-economic environment also helps in the growth, sustainability and success of an entrepreneurial activity as stated by [12]. Environmental variables are also relevant, not only in that they open up opportunities to exploit market inefficiencies or gaps, as an approach in economy, but as different environment produce different results thus success or failure.

[19] explained entrepreneurial environment as the overall economic, socio-cultural and political factors that influence people's willingness and ability to undertake entrepreneur activity. But other factors in the environment will affect the willingness of individual from entering entrepreneurial activities other done what has being stated by [18]. These are the demographic and natural environment forces. Governmental and legal variables also drive individuals in pursuing an entrepreneurial activity.

Other principal factors that entrepreneurs consider before entering entrepreneurial processes and activities include labour market regulations, government fiscal environment, administrative complexities, patent, licensing and bankruptcy law, education and skills upgrading [20]. Accessing financial resources is another factor that drives entrepreneurship. In the developing countries, the environmental factors that are mostly considered for infrastructure availability include water, electricity, tarred roads and telecommunication.

\section{Methodology}

The target population for the study was artisans and craftsmen in the Kumasi Metropolis. Multi-stage sampling 
procedure was used for the study. The first stage of the sampling selected Kumasi Metropolis purposively, mainly of its profile; it is the second largest city in Ghana and most commercial center in the Region and houses the rich culture of Ghana and all forms of artisans and craftsmen with great history and tradition. The second stage was the selection of the twelve (12) towns within the Metropolis for the study. The final stage was the selection of eleven (11) types of businesses with allocated target for each business as shown in Table 1.

The criteria that influence the sample size was that the artisan or craftsman business should be classified under small and medium scale enterprises and it should have been operated for at least two years. The business owner should have skills for at least one of the artifact he/she sells. Also individuals who worked in firms or construction should have been with the firm for at least two years.

\begin{tabular}{cccc} 
Table 1. Sample profile. & & & \\
\hline Location of Business & Number & Type of Business & Number \\
\hline Kejetia & 2 & Mechanics & 3 \\
Bantama & 3 & Metal Works & 2 \\
Adum & 3 & Construction & 2 \\
Asuofia Asaman & 1 & Carpentry \& Furniture & 4 \\
Tech Junction & 3 & Hair Artist & 3 \\
Top High & 1 & Art \& Craft & 8 \\
Asokwa & 3 & Dress Making & 3 \\
Suame & 3 & Bag Making & 2 \\
Atonsu & 6 & Baking & 1 \\
Ahinsan & 2 & Catering & 1 \\
Ntensere & 1 & Clay Work & 1 \\
Ahwia & 1 & - & - \\
Total & $\mathbf{2 9}$ & Total & $\mathbf{3 0}$ \\
\hline
\end{tabular}

Source: Author's construct, September 2014.

\subsection{Data Collection}

A structured questionnaire was used to collect data on the entrepreneurship factors at the individual, firm and the environmental level. The questionnaire consists of three parts: the socioeconomic characteristics of the respondents, determinants of entrepreneurship and its challenges. A Likert scale was used to measure these pertinent constructs of the questionnaire.

A Likert scale was used to indicate the responses from the respondents to measure the individual, firm and environmental determinants of entrepreneurship. The results were presented using percentages, mean values, standard deviations and Relative Importance Index (RII). The mean values, standard deviations as well as the RII were calculated using the five point Likert scale $(1=$ strongly disagree, $2=$ disagree, $3=$ neutral, $4=$ agree and $5=$ strongly agree). The questionnaires were administered in the form of a face-to-face interview. The interview proved essential because of the low literacy level of the respondents and the sensitivity of the subject matter under study.

We acknowledge that, considering the cultural and geographical spread of the artisans and the craftsmen sector in the Metropolis, the survey may not be representative of either the Metropolis or Ghana at the national scale. Nevertheless, it does provide cross-sectional data of various artisans and craftsmen in the informal work and is one of the first surveys to explore the determinants of entrepreneurship of artisans and craftsmen in informal work in Ghana.

\subsection{Data Analysis}

The analysis was aided by the use of Statistical Package for the Services Solution (SPSS) where the scores assigned to each factor by the respondents were entered and consequently the responses from the questionnaires were subjected to statistical analysis for further insight. The results were presented using percentages, mean values, standard deviation and Relative Importance Index (RII). The standard deviation measures the degree of deviation to theme/statement outline while mean is the degree of consensus to the theme/statement outline. The contribution of each of the factors to overall determinants of individual, firm and the environment was examined and the ranking of the attributes in terms of their criticality as perceived by the respondents was done by the use of Relative Importance Index (RII) which was computed using Equation (1). 


$$
\mathrm{RII}=\text { Sum of weights }(\mathrm{W} 1+\mathrm{W} 2+\mathrm{W} 3+\cdots+\mathrm{Wn}) / \mathrm{A} \times \mathrm{N}
$$

where:

$\mathrm{W}=$ weights given to each factor by the respondents and will range from 1 to 5 with " 1 " being less significant and "5" being extremely significant;

A = highest weight on the Likert scale (i.e.: 5 in our case), and;

$\mathrm{N}=$ total number of respondents.

\section{Results and Discussion}

\subsection{Socioeconomic Characteristics of the Respondents}

Twenty-three (23) out of the thirty (30) respondents were males representing $76.7 \%$ constituted the majority whereas seven (7) of the respondents representing $23.3 \%$ were females. The skewed resulted in favour of male may be attributed to the nature of the job. The dominance of men over women from the information gathered attributed to the fact that running your own business is demanding, hard work and time consuming, therefore it needs people who are very strong, smart and mentality strong. In the Kumasi Metropolis majority of the females are into selling and buying of goods and services to sustain their families. On the educational level, the results indicated that fifteen (15) out of thirty respondents representing 50\% had Secondary education, whilst nine (9) of the respondents representing $30 \%$ had Tertiary education and six (6) had primary education representing $20 \%$. The low level qualification here shows education in the formal setting is not everything as vocational skills based on creativity and innovation is the bases of the craftsmen and artisans secret to success.

The businesses are metal works, construction, carpentry, hair stylist, art \& craft, dress making, bag making, baking, catering and clay work. This shows a well distributed survey. The location of the various businesses also show a wide spread of this survey. It also gives an idea about the concentration of some particular works. This can be related to the fact that such businesses shall be concentrated in particular area especially works like hair making and dress making. The number of years of operation of a business can be an indication that they are doing the right things right that is why they are still in business. The result depicts that $18(60 \%)$ falls within the range of ( 1 - 10 years) while $9(30 \%)$ represents (11 - 20 years). The generational businesses made $3(10 \%)$ of the respondents. On the age of the respondents ( 25 - 34 years) was the dominant one with $66.7 \%$ representing 20 respondents while the rest had $33.3 \%$, it is difficult to tell if they are genuine entrepreneurs or situation has pushed them into that field due to lack of formal employment opportunities.

\section{Explanation of the Columns in the Tables in This Study}

In order to answer the questions, a statement was made for the respondent to give the extent of agreement or disagreement on the factors that determine entrepreneurial processes and activities for the individual, the firm and the environment as well as the challenges. This was rank and weighted as: Strongly Agree (SA) = 1; Agree $(A)=2$; Not Sure $(N)=3$; Disagree $(D)=4$; Strongly Disagree $(S D)=5$.

Relative Importance Index was used to rank the different factors in the three determinants as well as the challenges. To measure the relative importance of each factor or variable used, indices of range $0.85-1.00=$ High importance; $0.61-0.84=$ Medium importance; $0.00-0.60=$ Low importance. The three (3) topmost ranked factors or variables of high importance, according to the calculated RII, are discussed to throw further light on the drivers of entrepreneurial processes and activities in Kumasi Metropolis.

\subsection{Determinants of Entrepreneurship}

\subsubsection{Individual Determinants of Entrepreneurship}

Table 2. Individual determinants of entrepreneurship.

\begin{tabular}{|c|c|c|c|c|c|c|}
\hline Variable & SA & A & $\mathrm{N}$ & $\mathrm{D}$ & SD & Total \\
\hline Personal traits & $16(53 \%)$ & $8(27 \%)$ & $4(13 \%)$ & 0 & $2(7 \%)$ & 30 \\
\hline Desire for profit & $15(50 \%)$ & $10(33 \%)$ & $2(7 \%)$ & $2(7 \%)$ & $1(3 \%)$ & 30 \\
\hline Skills, knowledge and prior experience & $9(30 \%)$ & $18(61 \%)$ & $1(3 \%)$ & $1(3 \%)$ & $1(3 \%)$ & 30 \\
\hline Social ties and network & $8(27 \%)$ & $10(33 \%)$ & $4(13 \%)$ & $3(10 \%)$ & $5(17 \%)$ & 30 \\
\hline Parental work background & $6(20 \%)$ & $5(17 \%)$ & $4(13 \%)$ & $4(13 \%)$ & $11(37 \%)$ & 30 \\
\hline
\end{tabular}

Source: Field Data, September 2014. 
From the result (Table 2), a little over half the respondents strongly agreed that personal traits namely confidence, passion and tenacity lead an individual into entrepreneurial processes and activities. $27 \%$ also agree to the same fact that these factors will make someone become entrepreneur. A total of $80 \%$ of the sample agreeing to this statement confirms that personal traits are a determining factor for entrepreneurial activities [13]. 7\% of the respondents strongly disagreed with the fact that personal trait lead to entrepreneurship. Even though 13\% were not certain about this factor, it can be deduced that $80 \%$ of the population agreed to this statement and hence it confirms the earlier theories. Confidence, Passion and Tenacity were the main personal traits and this confirms [11] and [16].

The result shows that $50 \%$ of the respondents strongly agreed to the fact that the desire for profit will make them start entrepreneurial processes and activities and $33 \%$ of the respondents also agreed to this same fact. Even though it can be confirmed that desire for profit lead people into entrepreneurship, it should be noted that about $10 \%$ disputed this fact. $10 \%$ of the populations also were not sure if profit will lead them into entrepreneurship. Desire for profit and increase individuals' income is confirmed as a non-psychological factor that causes entrepreneurship in individuals [3].

A $60 \%$ of the respondents agree that skills, knowledge and prior experience drive entrepreneurial processes and activities in an individual per the analysis. But 30\% strongly agree to this fact insinuating that without those factors an individual cannot start any entrepreneurial processes and activities. A 3\% of the respondents strongly disagreed to this, the reason being that people buy and sell products they have no skills, knowledge or prior experience on. Another $3 \%$ also disagreed to this fact. The remaining $3 \%$ were not certain if this will really affect entrepreneurship. This confirms the works of [13] that prior experience is one of the factors that cause individuals into entrepreneurship.

Result shows that social ties and network were established by $60 \%$ of the respondents that it influenced their ability to start entrepreneurial processes and activities, with $27 \%$ out of the $60 \%$ strongly agreeing to this fact. A $27 \%$ of the respondents disagree that social ties and network will make them go into entrepreneurial processes and activities. $17 \%$ out of the $27 \%$ strongly oppose to this fact. $13 \%$ of the respondents neither agree nor disagree to this fact. They believe to some extent social ties and network can lead an individual into entrepreneurship but on the other hand the fact that they are not investing funds into the business, they cannot affect one's ability to be entrepreneurial. It can be deduced from this analysis that social ties and network drives entrepreneurship based on the $60 \%$ of the sample size which confirms this from the literature review [15].

Parental work background in the case of entrepreneurship from the analysis did not cause majority of the respondents into starting entrepreneurial processes and activities even though $20 \%$ strongly agreed and $17 \%$ also agreed to this fact. The majority is made up of $50 \%$ of the respondents who strongly disagreed and disagreed to this fact. $13 \%$ of the respondents neither agree nor disagree to this fact. $50 \%$ of the sample size disagreement insinuates that parental work background does not drive entrepreneurship. Though [14] considers the parent's job as an influence on entrepreneurial process but this response shows that it is a weak determinant.

\subsubsection{Firm Determinants of Entrepreneurship}

The result (Table 3) shows that, $63 \%$ of the respondents agreed that firm policy that support entrepreneurship in the form of innovativeness made them entrepreneurial. Apprentice, trainees and employees who were not working in very big firm were part of the $63 \%$. They testify that even though their business do not have written policy, their employers have made it clear to them that they can bring new ideas on how things are done and also they confirm that their employers listen to their ideas whenever they send it. 3\% of the population disagreed to this statement and another 33\% think a supportive policy does not affect them or make any difference. Also the artisans and craftsmen who were working alone also picked not sure. [17] study on the firm factors that drive entrepreneurship is confirmed with the $63 \%$ of the sample's agreement.

Table 3. Firm determinants of entrepreneurship.

\begin{tabular}{|c|c|c|c|c|c|c|}
\hline Variable & SA & A & $\mathrm{N}$ & $\mathrm{D}$ & SD & Total \\
\hline Company policy support & 0 & $19(64 \%)$ & $10(33 \%)$ & $1(3 \%)$ & 0 & 30 \\
\hline Top management support & $1(3 \%)$ & $18(61 \%)$ & $10(33 \%)$ & 0 & $1(3 \%)$ & 30 \\
\hline Department competition & 0 & $7(23 \%)$ & $18(61 \%)$ & $4(13 \%)$ & $1(3 \%)$ & 30 \\
\hline Firm motivation or reward & $4(13 \%)$ & $7(23 \%)$ & $10(33 \%)$ & $6(20 \%)$ & $3(10 \%)$ & 30 \\
\hline
\end{tabular}

Source: Field Data, September 2014. 
The result (Table 3) shows that $63 \%$ of the respondents both strongly agreed and agreed that they either give their support to bring about innovation or they receive support from their top management which made them come out with different materials, methods and processes in their art and craft works. A 3\% strongly disagreed to this, stating that their support does not make a difference if there are no resources available to carry out the said innovation. Another 33\% neither agreed nor disagreed, stating that top management might verbally make those statements but they blush off any idea that is given them. A couple of people worked alone so they could not agree nor disagree on this statement. This factor is also confirmed as a determining factor even though the percentage of people is less than $50 \%$. This could attribute to the number of people who were sole proprietor could not agree nor disagree to the statement. Hence it firmly confirms [17] study.

From the result majority of the artisans and craftsmen neither agree nor disagree (60\%) that department or workers who are grouped to carry out a particular job in a firm or business brings about competition which lead to innovativeness. Others had no idea about it since they worked alone. A $23 \%$ of the respondents agreed to it that when workers are put in department they compete among themselves which bring out innovation. Others thus $13 \%$ and $3 \%$ disagree and strongly disagree respectively to this statement. There was no one in this sample who strongly agreed to this statement. Comparing the number of people who disagree to those who agreed, this factor is marginally confirms as a determining factor for entrepreneurship.

The result shows that $13 \%$ of the sampled respondents strongly agreed plus $23 \%$ agreed that a form of motivation or reward bring out the entrepreneurship in them, the managers also noticed it causes them to receive new ideas and ways from their employees, trainees or apprentice. A $10 \%$ who strongly disagreed plus a $20 \%$ who also disagreed that motivation or reward does not bring about innovativeness. Some managers think they made their input in the final works so there is no need to motivate workers and their ability to bring new product is a good training for their career. 33\% of the respondents were not sure whether motivation or reward causes any difference in being innovative. [3] studies can be confirmed that firm motivation or reward bring about entrepreneurship based on 36\% agreeing against 30\% disagreeing. The sampled population response was not conclusive which make it a weaker determinant.

\subsubsection{Environmental Determinants of Entrepreneurship}

Table 4. Environmental determinants of entrepreneurship.

\begin{tabular}{lcccccc}
\multicolumn{1}{c}{ Variable } & $\mathrm{SA}$ & $\mathrm{A}$ & $\mathrm{N}$ & $\mathrm{D}$ & $\mathrm{SD}$ & Total \\
\hline Accessing financial assistance & $20(67 \%)$ & $7(23 \%)$ & $2(7 \%)$ & $1(3 \%)$ & 0 & 30 \\
Patent & $5(17 \%)$ & $8(27 \%)$ & $13(43 \%)$ & $1(3 \%)$ & $3(10 \%)$ & 30 \\
Taxes and subsidies & $14(47 \%)$ & $11(36 \%)$ & $2(7 \%)$ & 0 & $3(10 \%)$ & 30 \\
Infrastructure & $9(30 \%)$ & $10(33 \%)$ & $6(20 \%)$ & $2(7 \%)$ & $3(10 \%)$ & 30 \\
Economic stability & $17(57 \%)$ & $12(40 \%)$ & $1(3 \%)$ & 0 & 0 & 30 \\
\hline
\end{tabular}

Source: Field Data, September 2014.

From the result (Table 4), it is realized that $67 \%$ of the respondents strongly agree that environmental factor like accessing financial assistance drive entrepreneurship. $23 \%$ also agree to this same environmental factor. A $7 \%$ of the respondents were not sure that accessing financial assistance will lead to entrepreneurship. And a 3\% did not agree to this factor and its effect. $67 \%$ of the respondents confirm that accessing financial assistant drives entrepreneurial activities as reported by [13]. This implies that to the sampled population this factor is a major determinant of entrepreneurship.

The result (Table 4) indicated that 17\% strongly agree that patent of work will bring about entrepreneurship. Also a $27 \%$ agreed to this fact. $43 \%$ who are also the majority were not sure if patent will lead to entrepreneurial activities. They think the designs and products visible features can be used by any other person and hence it would not cause any effect on entrepreneurship. A 3\% artisans and craftsmen disagreed that patent of products and design will drive entrepreneurial processes and activities. $10 \%$ of the artisans and craftsmen also strongly disagree that this will cause any entrepreneurship. With a total of $43 \%$ of the sample size agreeing to the statement, it then confirms patent as a driver of entrepreneurship [13].

The result shows the following, $47 \%$ artisans and craftsmen strongly agree that government taxes and subsides can cause entrepreneurial processes and activities; $37 \%$ also agreed to this; a $7 \%$ are not sure; no one disagree and $10 \%$ strongly disagree that governmental taxes and subsides will lead to entrepreneurship. Some of 
these artisans and craftsmen do not pay any taxes so subsides would not make any difference. Governmental taxes exemption and subsides enjoyed by potential entrepreneurs is confirmed per the high percentage agreement and it is in line with [13] literature. This can be attributed to the fact that goods/products are on small scale and patent is not critical thereby making it a weak determinant of entrepreneurship.

From the result, 33\% artisans and craftsmen agreed that infrastructure can make them or others engage in some entrepreneurial processes and activities. $30 \%$ of the artisans and craftsmen strongly agree to this. A total of $17 \%$ of the respondents disagree and strongly disagreed that infrastructure availability will make people or they themselves enter into entrepreneurship. A $7 \%$ of the respondents were not sure if infrastructure availability or development will lead to entrepreneurship. [19] cited that availability of physical infrastructures like communication, utilities, transportation and land causes entrepreneurial activities and this is confirmed by the $63 \%$ of the respondents.

The result indicated that with the exception of 3\% artisans and craftsmen who are not sure if economic stability will affect them to be entrepreneurial the rest of the respondents either strongly agree or agree that economic stability drives entrepreneurial processes and activities. Economic stability is confirmed as a factor that drives entrepreneurship with $97 \%$ of the respondents strongly agreeing to the statement and this confirms [18].

\subsection{Challenges of Entrepreneurial Processes and Activities}

Table 5. Challenges of entrepreneurial processes and activities.

\begin{tabular}{|c|c|c|c|c|c|c|}
\hline Variable & SA & A & $\mathrm{N}$ & $\mathrm{D}$ & SD & Total \\
\hline High technology & $7(23 \%)$ & $9(31 \%)$ & $7(23 \%)$ & $6(20 \%)$ & $1(3 \%)$ & 30 \\
\hline High initial capital & $10(33 \%)$ & $14(47 \%)$ & $3(10 \%)$ & $1(3 \%)$ & $2(7 \%)$ & 30 \\
\hline Entrepreneurs do not get the required training & $14(47 \%)$ & $1(3 \%)$ & $6(20 \%)$ & $8(27 \%)$ & $1(3 \%)$ & 30 \\
\hline Unreadily availability of required labour and skills & $5(16 \%)$ & $8(27 \%)$ & $1(3 \%)$ & $8(27 \%)$ & $8(27 \%)$ & 30 \\
\hline Unreadily availability of materials & $2(7 \%)$ & $8(27 \%)$ & $6(20 \%)$ & $7(23 \%)$ & $7(23 \%)$ & 30 \\
\hline Unreadily availability of equipment & $2(7 \%)$ & $19(63 \%)$ & $4(13 \%)$ & 0 & $5(17 \%)$ & 30 \\
\hline Dominant Policies & $1(3 \%)$ & $13(44 \%)$ & $9(30 \%)$ & $4(13 \%)$ & $3(10 \%)$ & 30 \\
\hline High taxation & $7(23 \%)$ & 0 & $5(17 \%)$ & $13(43 \%)$ & $5(17 \%)$ & 30 \\
\hline No business plan for acquisition of capital from financial institution & $24(81 \%)$ & $4(13 \%)$ & $1(3 \%)$ & $1(3 \%)$ & 0 & 30 \\
\hline Non stability of the industry & $5(17 \%)$ & $7(23 \%)$ & $10(33)$ & $5(17 \%)$ & $3(10 \%)$ & 30 \\
\hline Little or no knowledge in the firm or product & $13(44 \%)$ & $7(23 \%)$ & $4(13 \%)$ & $5(17 \%)$ & $1(3 \%)$ & 30 \\
\hline
\end{tabular}

Source: Field Data, September 2014.

From the result (Table 5), 23\% of the artisans strongly agree that high technology is a challenge; $31 \%$ of the artisans also agree that high technology is a challenge. The main reason which was associated with this is that even though acquiring a high technology machines will increase their production, they are not readily available and it is also costly. Others also gave the view that high technology has imposed a threat to their sales. $3 \%$ of the artisans strongly disagree to this statement whilst $20 \%$ of them also disagree to this statement. These artisans stated that they do not require high technology machines for their work. Others also think they can easily get it rented for their work. $23 \%$ of also do not agree nor disagree with the statement. The possible explanation to this finding is attributed to the fact that the artisans can do their work without the technology due important.

It can be deduced from the result (Table 5) that $80 \%$ of the artisans and craftsmen agreed to the statement that high initial capital is a challenge for entrepreneurial activities by strongly agreeing and agreeing respectively. $10 \%$ also disagreed to the statement and the reason was that they do not require high capital for their work whilst others also stated that they will do with the finance they have till it is appreciated to do high initial capital business. $10 \%$ of the population was not sure about the answer to give for this statement. The finding provided evidence that most people with endow skills without initial capital cannot be entrepreneurs. Half of the respondents agree to the statement that entrepreneurs do not get the required training that is both technical and business from the result. $20 \%$ of the respondents were indifferent to that factor while $30 \%$ of the sampled population disagreed to this statement because they stated there is training institution that they can attend if they are ready. This finding confirms the fact that there is no specialized training institute for entrepreneur's craftsmen and artisans on how to manage and run their business. 
Furthermore, 54\% disagree and strongly disagree to the statement that required skills and labour are not readily available. They stated that the skills and labour are available only if they are ready to pay them. Others emphasize that they take apprentice and trainees so they would not need such labour. $16 \%$ strongly agree and $27 \%$ also agreed to the statement. They stated that labour might be available but they would not have the required skills, hence they need to train the labour that is acquired. Others also stated that since the work they do is tedious, it is difficult to get the required labour to do such work. $3 \%$ were indifferent on the statement.

From the result (Table 5), 46\% of the respondents either strongly disagreed or disagreed to the statement that materials are not easily available. Most of the artisans and craftsmen get their materials locally hence the answer given. $20 \%$ neither agreed nor disagreed to the statement. Their reason was that even though the materials are available, the quality is poor. $34 \%$ agreed that the statement is true. These artisans were mostly with big firms like construction companies.70\% of artisans strongly agreed and agreed that machines are not readily available. Most of such machines have to be imported. 17\% disagreed to this statement. These artisans stated they do not require high technology machines only simple tools which are readily available on the market. $13 \%$ neither agreed nor disagreed to the statement.

From the result, $44 \%$ of the respondents agree to the statement that there are dominant policies in the industry. $3 \%$ also strongly agree to this statement. $30 \%$ neither agreed not disagreed to the statement. A $10 \%$ of the sample size strongly disagreed to the statement whilst a $13 \%$ disagree to this statement. Furthermore, $60 \%$ of the respondents disagreed that taxation is a challenge. Their reason was that they mostly operate from their homes and taxes do not apply to their works. Others also stated that they only pay Kumasi Metropolitan Assembly (KMA) for the land they are occupying to do their work. 23\% of the respondents strongly agreed that high taxation is a challenge. Most of these people work in big firms and they pay taxes.

From Table 5, 81\% of the respondents strongly agreed to this statement and that they do not know what a business plan is and its importance. 13\% of the respondents also agreed to this statement. After they knew what a business plan is, they acknowledge they do not have a business plan and also agreed that a bank will require such document to give a business a loan to operate on. $3 \%$ of the sample size disagreed to this fact stating that they have such plans in mind. Another $3 \%$ of the population was not sure on this statement. The possible explanation for this finding is attributed to the fact that entrepreneurs normally concentrate on their technical knowledge at the expense of the business side of entrepreneurship. Furthermore, $17 \%$ strongly agreed that the industry was not stable and a $23 \%$ also agreed that the industry was not stable. $33 \%$ was not sure on the statement. A total of $27 \%$ of the respondents disagreed to this statement. The reason for this is that they believe they do not have an industry so there would not be any stability or not.

It was deduced from the result that a total of $67 \%$ of the respondents believed that there are people who are operating business who have no knowledge of the business or the product. A total of $20 \%$ strongly disagreed and disagreed to this statement. The reason was that without the needed knowledge, no one can do the kind of work they are doing. A $13 \%$ of the sample size was neutral to the statement.

\subsection{Relative Importance Index (RII) of Determinants of Entrepreneurship}

To measure the relative importance of each factor or variable used, indices of range $0.85-1.00=$ High importance; 0.61 - 0.84 = Medium importance; 0.00 - 0.60 = Low importance.

\subsubsection{RII for Individual Determinants of Entrepreneurship}

Table 6. RII for individual determinants of entrepreneurship.

\begin{tabular}{cccccc}
\hline Individual Determinants & Mean & Std. Dev. & RII & Rank & RII Index \\
\hline Personal traits & 4.2 & 1.126 & 0.84 & $2^{\text {nd }}$ & Medium Importance \\
Desire for profit & 4.23 & 1.04 & 0.846 & $1^{\text {st }}$ & High Importance \\
Skills, knowledge and prior experience & 4.1 & 0.885 & 0.82 & $3^{\text {rd }}$ & Medium Importance \\
Social ties and network & 3.43 & 1.431 & 0.687 & $4^{\text {th }}$ & Medium Importance \\
Parental work background & 2.7 & 1.601 & 0.54 & $5^{\text {th }}$ & Low Importance \\
Unweighted mean & 3.732 & & & & \\
\hline
\end{tabular}

Source: Field Data, September 2014. 
From the result (Table 6), among the individual determinant for entrepreneurial activities and processes, the RII that ranked $1^{\text {st }}$ is the desire for profit, it is then followed by personal traits and skills, knowledge and prior experience is the third $\left(3^{\text {rd }}\right)$ highest. Social ties and network comes as the fourth factors and finally parental background is the fifth $\left(5^{\text {th }}\right)$ highest. Desire for profit's RII falls in the range of high importance. Some people believe they get into entrepreneurial processes because of the passion they have for it, but it can be deduced that profit is paramount in any entrepreneurial business. Such a factor cannot be substituted and most individual will get to any extend to get the profit. The $2^{\text {nd }}$, $3^{\text {rd }}$ and $4^{\text {th }}$ individual determinants all fall within the medium importance for the RII index of range. This means that any of the three can be substitute for another a time "t" based on the environment and the entrepreneurial processes available. Parental work background falls within the low importance range of indices. This means that individuals would not be affected by their parent's work to enter into entrepreneurial processes. The unweighted mean for individual determinant is 3.732 .

\subsubsection{RII for Firm Determinants of Entrepreneurship}

Table 7 indicates that both Company Policy Support and Top Management Support were ranked $1^{\text {st }}$ among all the four determining factors in the firm, its followed by Firm Motivation or Reward, it was rated by the artisans and craftsmen as the second factor that causes entrepreneurship to start in firms and the last determinant was Departments in Firm. The rating for department competition leading into innovation in the firm was very low which means majority of respondents do not agree to this statement. It can also be deduced that such determinants are available but it is on a very small scale or it's in high innovative firms. It can also be noted that the $1^{\text {st }}$, $2^{\text {nd }}$ and $3^{\text {rd }}$ rank for the firm determinants on the RII lies within the medium importance range but close to the minimum range. Its unweighted mean is 3.33 .

Table 7. RII for firm determinants of entrepreneurship.

\begin{tabular}{|c|c|c|c|c|c|}
\hline Firm determinants & Mean & Std. Dev. & RII & Rank & RII Index \\
\hline Support from company policy & 3.6 & 0.563 & 0.72 & $1^{\text {st }}$ & Medium importance \\
\hline Top management support & 3.6 & 0.724 & 0.72 & $1^{\mathrm{st}}$ & Medium importance \\
\hline Department competition & 3.03 & 0.718 & 0.606 & $3^{\text {rd }}$ & Medium importance \\
\hline Firm motivation or reward & 3.10 & 1.185 & 0.62 & $2^{\text {nd }}$ & Medium importance \\
\hline Unweighted mean & 3.33 & & & & \\
\hline
\end{tabular}

Source: Field Data, September 2014.

\subsubsection{RII for Environmental Determinants of Entrepreneurship}

Ranking the environmental determinants for entrepreneurial activities and processes according to Relative Importance Index are as follows: accessing financial assistance and economic stability rank first, government policy like taxes and subsides rank second, infrastructure ranks third and finally patent rank four as shown in Table 8.

Table 8. RII for environmental determinants of entrepreneurship.

\begin{tabular}{|c|c|c|c|c|c|}
\hline Environmental determinants & Mean & Std. Dev. & RII & Rank & RII Index \\
\hline Accessing financial assistance & 4.53 & 0.776 & 0.906 & $1^{\text {st }}$ & High importance \\
\hline Patent in the industry & 3.37 & 1.129 & 0.673 & $4^{\text {th }}$ & Medium importance \\
\hline Taxes and subsides & 4.1 & 1.213 & 0.82 & $2^{\text {nd }}$ & Medium importance \\
\hline Infrastructure development & 3.67 & 1.269 & 0.733 & $3^{\text {rd }}$ & Medium importance \\
\hline Economic stability & 4.53 & 0.571 & 0.906 & $1^{\text {st }}$ & High importance \\
\hline Unweighted mean & 4.04 & & & & \\
\hline
\end{tabular}

Source: Field Data, September 2014.

This means that there will be more entrepreneurial processes and activities if individuals or firms can get access to financial assistance and this factor has the same weight as that of economic stability. Getting government policies like taxes and subsides for business is the next important factor that will bring about the introduc- 
tion of new market, new products, new services and new methods. Availability of infrastructure is the third most important factors that individuals and firms need to be entrepreneurial.

Lastly, individuals and firms will be entrepreneurial if there is patent in the industry. Patent being last among the five shows how the industries do not give much important to intellectual property right or patent. This also means innovative will easily be copied to reduce the profit flow associated with it. Even though individuals have a high desire for profit in order to become an entrepreneurial, they do not wish to protect their intellectual property.

Access to financial assistance and economic stability, both fall in the high important indexes of RII. The higher the access of financial assistance and economic stability, the higher individuals will start entrepreneurial processes and activities. Firms will also become innovative if these two factors are high. If these two factors move to negativity, thus low most individuals and firms will move away from entrepreneurial activities even including those which have low initial capital. The easiness it is to access financial assistance and the stable the economy of the country, the lower the rate of poverty and stagnation of firms. Government policies like taxes and subsides lies within the medium importance. Infrastructure and patent also lie within the medium importance. Its unweighted mean is 4.04 .

\subsubsection{RII for Challenges of Entrepreneurship}

Table 9 shows the relative importance index and its rank for challenges of entrepreneurship for artisans and craftsman in Kumasi Metropolis.

Table 9. RII for challenges of entrepreneurship.

\begin{tabular}{|c|c|c|c|c|c|}
\hline Challenges & Mean & Std. Dev. & RII & Rank & RII Index \\
\hline No business plan for acquisition of capital from financial institution & 4.7 & 0.702 & 0.94 & 1 st & High importance \\
\hline High initial capital & 3.97 & 1.098 & 0.793 & 2nd & Medium importance \\
\hline Little or no knowledge in the firm or product & 3.87 & 1.252 & 0.773 & 3rd & Medium importance \\
\hline Entrepreneurs do not get the required training & 3.63 & 1.402 & 0.726 & 4th & Medium importance \\
\hline High technology & 3.5 & 1.167 & 0.7 & 5th & Medium importance \\
\hline Unreadily availability of equipment & 3.43 & 1.194 & 0.686 & 6th & Medium importance \\
\hline High taxation & 3.3 & 1.418 & 0.66 & 7th & Medium importance \\
\hline Dominant policies & 3.22 & 1.204 & 0.643 & 8th & Medium importance \\
\hline Non stability of the industry & 3.2 & 1.215 & 0.64 & 9th & Medium importance \\
\hline Unreadily availability of required labour and skills & 2.79 & 1.544 & 0.558 & 10th & Low importance \\
\hline Unreadily availability of materials & 2.7 & 1.291 & 0.54 & 11th & Low importance \\
\hline
\end{tabular}

Source: Field Data, September 2014. Its unweighted mean is 3.483.

Entrepreneurs not having business plan was range high among the other challenges through respondent's answers. It makes it very critical due to the other effect it can cause their businesses. If entrepreneurs are taught or trained on how to prepare business plan, it will effectively lead them to acquire financial loans and also help in the growth of their establishments. The two low importance determinants is a challenge but it is not a very intensive one especially for entrepreneurs that use raw materials from Ghana. A lot of the challenges fall within the medium importance range. These challenges can be solved in the medium term. Its effects would not be as critical as the lack of business plan.

\section{Conclusion and Recommendation}

Entrepreneurship has recent time received important attention from various governments and scholars because of its adverse importance. In relation to this, it is very important for firms and governments to know the factors that drive such important entity in order to maximize it. This paper aimed to determine the individual, firm and environmental factors that drive entrepreneurial processes and activities and it challenges in Kumasi Metropolis, Ghana. Through the descriptive analysis used, the determining factors for entrepreneurial processes and activities for individuals, firms and environment were realized. The relative importance given to each determinant for 
individuals, firms and environment was also attained.

Our results seem to support a growing belief that entrepreneurship is very important in alleviating poverty. It is then very important that firms and government find ways to develop and grow the determining factors that are very important in birthing entrepreneurship. This means allocating the scarce available resources on the high important factors. This can also mean reducing the allocated resources available to the less important factors. Our study provides a strong support for the need of proper training and seminars programmes for the artisans and craftsmen on how to make their products meet standards and market their product to position their trade in a lucrative industry. It is critical that organizations and government must help create the environment and develop the factors that can bring about entrepreneurial processes and activities.

The study also encourages that firms should make their policy support entrepreneurial activities and processes, and the top management should support it. The support from the company and top management serves as a motivation as well as insurance for being entrepreneurial. The risk involves being sacked if an idea or process does not work which is eradicated. There is lots of importance when a firm is entrepreneurial especially innovative. Firms must introduce type of motivation or reward for workers who are innovative to drive more entrepreneurial activities. Among the various challenges that were located, it was realized that the major challenge of artisans is that they do not have business plan; the implication of this is that they cannot access funds from banks and also would not have future plans for their business expansion and growth. The third most challenge was that some entrepreneurs have little or no knowledge in the firm that they are operating. This leads to inefficiency and collapsing of the business. It would be of benefit to critically give undivided attention on packages of accessing financial assistance of existing and potential entrepreneurs with backing of government policies to enhance and expand the entrepreneurship drive especially on the environmental factors on entrepreneurship.

However, the research also raises a number of other questions:

- What skills does an entrepreneur need to make its business successful?

- Why should the entrepreneur be bothered with a business plan?

- Why sustainability of businesses is critical in the informal sector?

The paper provided a multi-perspective approach to entrepreneurship supported by the relationship of the different level of determinants. The paper therefore suggests that the highest rank importance on individual, firm and the environment factors must be given a serious attention by policy makers, governments, non-governmental agencies and donors to alleviate poverty within the Kumasi Metropolis and its environs.

\section{References}

[1] United Nations (2012) The Millenium Development Goals Report. New York, USA.

[2] Ghana Statistical Services (2013) Millennium Development Goals in Ghana. 2010 Population \& Housing Census Report, Ghana Government.

[3] Shane, S. (2008) The Illusions of Entrepreneurship: The Costly Myths That Entrepreneurs, Investors, and Policy Makers Lie by. Yale University Press, New Haven \& London.

[4] Friis, C., Paulsson, T. and Karlsson, C. (2002) Entrepreneurship and Economic Growth: A Critical Review of Empirical and Theoretical Research. Swedish Institute for Growth Policy Studies, Stockholm.

[5] Fayolle, A. (2007) Entrepreneurship and New Value Creation: The Dynamic of the Entrepreneurial Process. Cambridge University Press, Cambridge. http://dx.doi.org/10.1017/CBO9780511488689

[6] Thomas, A.S. and Mullerer, S.L. (2000) A Case for Comparative Entrepreneurship: Assessing the Relevance of Culture. Journal of International Business Studies, 31, 287-301. http://dx.doi.org/10.1057/palgrave.jibs.8490906

[7] Lashley, C. and Lee-Ross, D. (2009) Entrepreneurship and Small Business Management in the Hospitality Industry. Butterworth-Heinemann, Oxford.

[8] Arindam, L. (2014) Measurement of Enterprise Development and Its Determinants in India: An Inter-State Analysis. Journal of Asia Entrepreneurship and Sustainability, X, 83-108.

[9] Butler, D. (2006) Enterprise Planning and Development: Small Business Start-Up Survival and Growth. ButterworthHeinemann, Oxford, UK.

[10] Longenecker, J.G., Moore, C.W., Petty, J.W. and Palich, L.E. (2008) Small Business Management—Launching and Growing Entrepreneurial Ventures. 14th Edition, Thomson South-Western, Mason.

[11] Hatten, T.S. (2012) Small Business Management: Entrepreneurship and Beyond. 5th Edition, South-Western Cengage Learning, Mason. 
[12] Ireland, R.D. and Barringer, B.R. (2012) Entrepreneurship: Successfully Launching New Ventures. 14th Edition, Pearson Education Inc., Upper Saddle River.

[13] Fuduric, N. (2008) The Sources of Entrepreneurial Opportunities: Individual and Environment. Aalborg University, Aalborg.

[14] Shane, S. (2003) A General Theory of Entrepreneurship. Edward Elgar, Cheltenham. http://dx.doi.org/10.4337/9781781007990

[15] Scarborough, N.M. (2012) Effective Small Business Management: An Entrepreneurial Approach. 10th Edition, Prentice Hall, Upper Saddle River.

[16] Marriot, S. and Lowe, R. (2006) Enterprise; Entrepreneurship and Innovation. Concepts, Context and Commercialisation. Butterworth-Heinemann, Oxford.

[17] Vliamos, S.J. and Tzeremes, N.G. (2012) Factors Influencing Entrepreneurial Process and Firm Start-Ups: Evidence from Central Greece. Journal of the Knowledge Economy, 3, 250-264. http://dx.doi.org/10.1007/s13132-011-0043-x

[18] York, J.G. and Venkataraman, S. (2010) The Entrepreneur-Environment Nexus: Uncertainty, Innovation, and Allocation. Journal of Business Venturing, 25, 449-465. http://dx.doi.org/10.1016/j.jbusvent.2009.07.007

[19] Jalali, S.H. (2012) Environmental Determinants, Entrepreneurial Orientation and Export Performance: Empirical Evidence from Iran. Serbian Journal of Management, 7, 245-255. http://dx.doi.org/10.5937/sjm7-1687

[20] Freytag, A. and Thurik, R. (2007) Entrepreneurship and Its Determinants in a Cross-Country Setting. Journal of Evolutionary Economics, 17, 117-131. http://dx.doi.org/10.1007/s00191-006-0044-2 